\title{
Treatment of recurrent trigeminal neuralgia due to Teflon granuloma
}

\author{
Hans-Holger Capelle $\cdot$ Almuth Brandis • \\ Christoph A. Tschan · Joachim K. Krauss
}

Received: 22 February 2010/Accepted: 6 April 2010/Published online: 24 April 2010

(C) Springer-Verlag 2010

\begin{abstract}
Recurrent trigeminal neuralgia after microvascular decompression (MVD) may be due to insufficient decompression, dislocation of the implant to pad the neurovascular contact, or the development of granuloma. Here, we report on our experience with Teflon granuloma including its treatment and histopathological examination. In a series of 200 patients with trigeminal neuralgia MVD was performed with Teflon felt according to Jannetta's technique. In three patients with recurrent facial pain Teflon granuloma was found to be the cause for recurrence. In each instance, the granuloma was removed for histopathological examination. Mean age at the first procedure was 62.3 years and at the second procedure 66.3 years. Recurrence of pain occurred between 1 and 8.5 years after the first procedure. MRI scans demonstrated local gadolineum enhancement in the cerebellopontine angle, and CT scans showed local calcification. Intraoperatively dense fibrous tissue was found at the site of the Teflon granuloma. Histopathological examination revealed foreign body granuloma with multinuclear giant cells, collagen-rich hyalinized scar tissue, focal hemosiderin depositions, and microcalcifications. The Teflon granuloma was completely removed, and a new Teflon felt was used for
\end{abstract}

H.-H. Capelle · C. A. Tschan · J. K. Krauss ( $\varangle)$ Department of Neurosurgery, Hannover Medical School, MHH, Carl-Neuberg-Str. 1, 30625 Hannover, Germany

e-mail: Krauss.Joachim@mh-hannover.de

A. Brandis

Institute of Pathology, Hannover Medical School,

30625 Hannover, Germany

Present Address:

C. A. Tschan

Department of Neurosurgery,

University Hospital Mainz, Mainz, Germany re-decompression. Patients were free of pain after the second procedure at a mean of 40.3 months of follow-up. Teflon granuloma is a rare cause for recurrent facial pain after MVD. Small bleeding into the Teflon felt at surgery might trigger its development. A feasible treatment option is surgical re-exploration, nerve preserving removal of the granuloma, and repeat MVD.

Keywords Trigeminal neuralgia - Facial pain . Microvascular decompression - Teflon granuloma

\section{Introduction}

Trigeminal neuralgia is characterized by sudden attacks of devastating facial pain. The onset of the attacks, with duration of a few seconds up to a minute, can be spontaneous or triggered by common daily activities such as eating, speaking, or touching the skin. Patients with trigeminal neuralgia live in fear of unpredictable painful attacks, which may lead to sleep deprivation and lifethreatening malnutrition. Furthermore, this condition can lead to irritability, severe anticipatory anxiety and depression [1-6].

There are several options for surgical therapy [4, 7-12] in patients with trigeminal neuralgia refractory to medical treatment. Since microvascular decompression (MVD) has been popularized by Jannetta in the 1980s [12-16], it is considered by many as the method of choice since it is the only method which may provide a definitive cure in the majority of patients. The intention of the operation is to pad the contact of an irritating arterial vessel with the trigeminal nerve. To achieve this goal, the most frequently used material nowadays is polytetrafluoroethylene (Teflon) $[5,7$, 13, 17-20]. 
In the largest series published by Jannetta, 1,185 patients underwent MVD. Of those, $64 \%$ of patients were free of symptoms without medication 10 years after surgery and $4 \%$ showed partial relief of pain. The annual rate of recurrence was $<2 \%$ after 5 years and $<1 \%$ after 10 years. Only $1 \%$ developed severe postoperative facial numbness and $0.3 \%$ required treatment for dysesthesia [5].

Recurrent trigeminal neuralgia, following MVD, may be due to insufficient operative techniques, dislocation of the Teflon implant, insertion of too much Teflon, or in the rare case, development of a granuloma [4, 21-25]. Little contigent information is available on the latter, and nerve sections have been deemed necessary to provide relief of pain [4].

Here, we report on our experience with the treatment of recurrent trigeminal neuralgia due to Teflon granuloma by removal of the mass and repeat MVD without nerve sacrifice.

\section{Methods}

In a series of 200 patients with idiopathic trigeminal neuralgia MVD was performed (JKK) according to the principles of Jannetta's technique [19]. The trigeminal nerve was approached via a small lateral suboccipital craniotomy in a modified prone "concorde" position. MVD was achieved interposing small pieces of Teflon felt between the trigeminal nerve and the offending vessel, fixed to this position by a small amount of fibrin glue.

In case of recurrent trigeminal neuralgia, patients underwent re-evaluation and, if possible, re-operation. Preoperatively, T2-weighted and gadolinium enhanced MRI-scans of the head and thin slice CT-scans were obtained. Patients underwent re-craniotomy and exploration of the trigeminal nerve at the cerebellopontine angle. In case of Teflon granuloma, microsurgical sharp dissection, preserving the trigeminal nerve and the corresponding vessel, with complete removal of the Teflon granuloma was performed. Then a new Teflon felt was placed between the trigeminal nerve and the vessel followed by fixation with fibrin glue. The removed granuloma was examined histopathologically in all cases.

\section{Results}

Overall eight patients in our series of 200 patients had recurrent pain. Six of them underwent reoperation (MVD), and in three of them (two men, one woman) a Teflon granuloma was identified. Mean age at the first MVD was 62.3 years, and at the operative re-exploration 66.3 years. All patients benefitted from complete relief of pain after surgery without side effects. The second operation was at an interval between 1 and 8.5 years (mean, 3.7 years) after the first procedure (Table 1).

Notably, as shown in Table 1 recurrence of trigeminal neuralgia was confined to the segments which were affected prior to the first operation only in one patient, while another segment become symptomatic in one instance, and a wider spread of pain was evident in the third patient. None of the patients had a longer-lasting neuropathic type of recurrent pain.

The overall incidence of Teflon granuloma in our series was three $(1.5 \%)$ out of 200 patients. In all three cases the granuloma had a gray-brownish appearance. It was found to be adherent both to the nerve and vessels, but it had also tight contact with the dura.

MR scans were indicative of a granuloma in one of the three patients (patient 2, see Fig. 1a-c). In this patient gadolineum enhancement was found at 1.5 years after the first MVD, raising the suspicion of an active granulomatous lesion. The MR scans of the other two patients did not reveal such findings. Nevertheless, areas of partial calcification within the Teflon interponate were detected in patient 1 (Fig. 1d, e).

Histopathological examination of the specimens in all three patients revealed a foreign body granuloma with birefringent Teflon filaments, engulfed by multinuclear giant cells and embedded in a collagen-rich hyalinized scar tissue with microcalcifications. Lymphocytes which were positive for "leucocytes common antigen (LCA)" were detected in varying frequency. Furthermore, there were hemosiderin-laden macrophages indicating previous hemorrhage within the Teflon felt (Fig. 2a-f).

Postoperative clinical examination revealed no new neurological deficits. As before, complete remission of the facial pain was achieved in all three patients. There were no complications like infection or cerebrospinal fluid leakage.

Table 1 Recurrent trigeminal neuralgia in 3/200 patients due to Teflon granuloma after microvascular decompression

\begin{tabular}{llllll}
\hline Patient & $\begin{array}{l}\text { Sex, age at } \\
\text { first operation }\end{array}$ & $\begin{array}{l}\text { Initial distribution } \\
\text { of trigeminal neuralgia }\end{array}$ & $\begin{array}{l}\text { Recurrent distribution } \\
\text { of trigeminal neuralgia }\end{array}$ & $\begin{array}{l}\text { Interval to second } \\
\text { operation }\end{array}$ & $\begin{array}{l}\text { Residual } \\
\text { symptoms }\end{array}$ \\
\hline 1 & M, 60 & $\mathrm{V} 1+\mathrm{V} 2$ & $\mathrm{~V} 3+$ Hypesthesia & 8.5 years & Hypesthesia \\
2 & $\mathrm{M}, 66$ & $\mathrm{~V} 2+\mathrm{V} 3$ & $\mathrm{~V} 2+\mathrm{V} 3$ & 1.5 years & None \\
3 & $\mathrm{~F}, 63$ & $\mathrm{~V} 2+\mathrm{V} 3$ & $\mathrm{~V} 1+\mathrm{V} 2+\mathrm{V} 3$ & Near \\
\hline
\end{tabular}


Fig. 1 Imaging studies of Teflon granuloma. a T2-weighted axial MR scan; $\mathbf{b}$ the enlarged view demonstrates a roundish hypointense spot within the mass corresponding to focal calcification; c axial T1-weighted MR scan of patient 2 revealed gadolineum enhancement at the location of MVD Teflon placement 1.5 years ago $\mathbf{d}$ thin sliced CT scans in patient 1 reveal hyperintense changes at the site where the Teflon felt was placed; e enlarged view
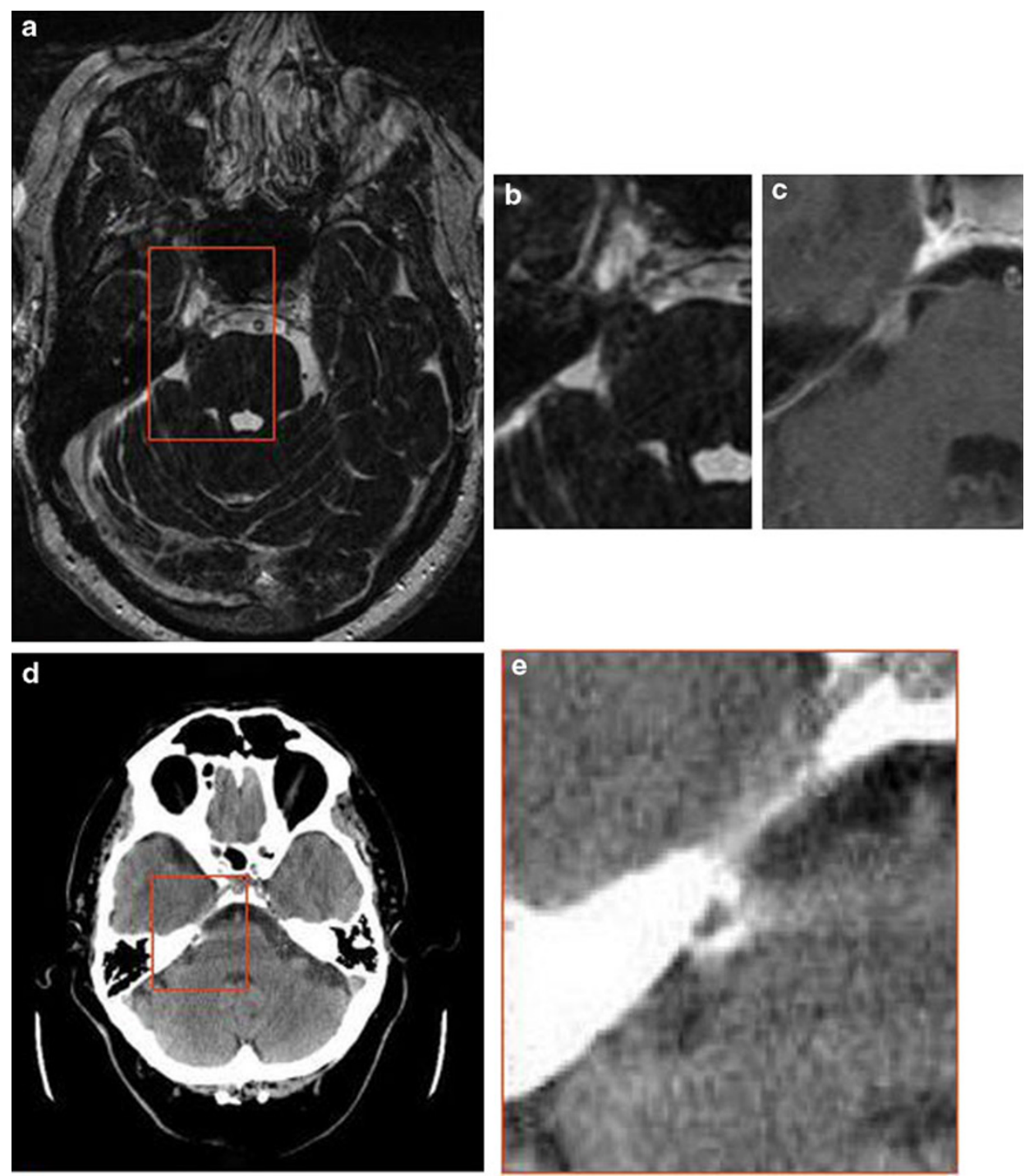

Preoperative medication was tapered off. At a follow-up of 40.3 months after the second surgery (range 39-43 months) no recurrence of facial pain was observed (Table 1).

\section{Discussion}

Microvascular decompression has several advantages as compared with other methods used to treat trigeminal neuralgia such as percutaneous procedures including thermocoagulation, glycerol injection or balloon compression of the Gasserian ganglion, and stereotactic radiosurgery. It is the procedure with the highest likelihood of providing a permanent cure [4-12, 26, 27]. In experienced hands, complications are rare and mortality is negligible. In particular, side effects such as anesthesia dolorosa or other types of neuropathic pain are less than that with other procedures. The most pivotal factor for excellent outcome is the surgeon's experience and meticulous attention to details during surgery. We have exclusively used Teflon for MVD procedures as it is common practice in most highload neurosurgical centers. Other materials that may be used to patch the neurovascular contact are muscle, cotton, Ivalon sponge, and others. Teflon felt has been thought to be an ideal material due to its tissue acceptance, the lack of resorption, little dislocation, and an overall low complication potential [24, 28, 29].

Nevertheless, Teflon is not such an inert material as it has been presumed initially. In other surgical disciplines, Teflon granuloma is a well-known histopathological diagnosis detected under various circumstances. Giant cell foreign body reactions are known in arthroplasty in orthopedic surgery, implants of the temporomandibular joint, or in several ENT-surgical procedures [28, 30-32]. 
Fig. 2 Histological examination showed foreign body granuloma with multinuclear giant cells (a Giemsa, × 100), containing birefringent Teflon fibers (b Elastica van Gieson, polarized light, $\times 100$ ). Positive immune staining of the giant cells for CD68 $(\mathbf{c} \times 200)$. Focal hemosiderin deposition indicating prior hemorrhage (d Prussian Blue, $\times 100$ ). In places, hyalinized scar tissue was found $(\mathbf{e} \mathrm{EvG}, \times 100)$ with microcalcifications (f, H\&E, $\times 200)$
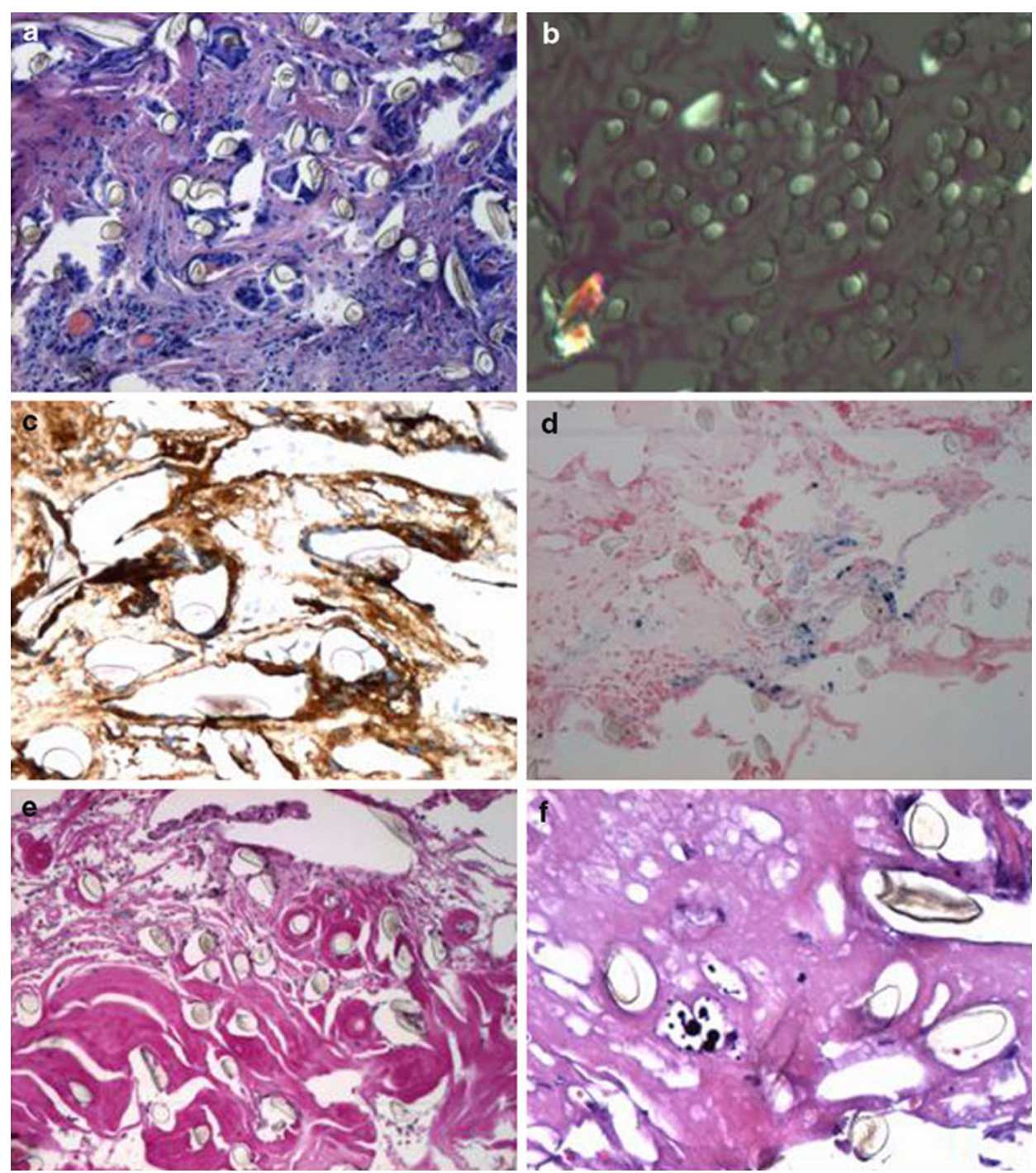

Teflon granuloma after MVD is hardly known among neurosurgeons, neurologists, and pain specialists. This is highly problematic, in particular in that far, that recurrent trigeminal neuralgia due to Teflon granuloma is like primary idiopathic trigeminal neuralgia a curable disorder. As indicated by a frequency of $1.5 \%$ in our series it is quite rare. Six previous studies have reported it to occur among $1.1-7.3 \%$ of patients (Table 2). In three of these studies, histopathological examination revealed microfragments of the Teflon felt surrounded by giant-cells resembling a granuloma formation $[21,22,25]$. Notably, however, the majority of studies on the outcome of trigeminal neuralgia after MVD have not even mentioned it, and Jannetta acknowledged in a comment to another study that he never discovered a Teflon granuloma (Jannetta-comment to Chen et al. [24]). In a recent series, which investigated explicitly the cause of recurrent facial pain after trigeminal MVD, it was found that 7 out of 29 patients $(24 \%)$ had a Teflon granuloma [4]. There are no pathognomonic signs and symptoms which indicate that recurrent trigeminal neuralgia after primary MVD is due to Teflon granuloma. Suspicion should be raised when recurrent pain affects other segments of the trigeminal nerve, which were not involved in the first place. Contrast enhancement on image studies indicate chronic inflammation and partly hypointense areas within the Teflon felt on T2-weighted MRI-scans or hyperdense areas on CT-scans may indicate calcification [24]. Normal preoperative MR scans do not exclude Teflon granuloma as the cause for recurrent trigeminal neuralgia.

Both the trigger and the development of Teflon granuloma related to MVD remain obscure since there is not any longitudinal study. Finally, the Teflon granuloma presents as a "tumor-like lesion" adherent to the nerve, vessels, and brainstem exerting a mass effect. The slow development of new pain not confined to the original segments and new deficits such as hypesthesia as well as the granulomatous appearance and calcification all indicate that the granuloma 
Table 2 Frequency of Teflon granuloma (literature review) after microvascular decompression for trigeminal neuralgia

\begin{tabular}{lll}
\hline Author & $\begin{array}{l}\text { Total number of } \\
\text { patients undergoing } \\
\text { microvascular } \\
\text { decompression }\end{array}$ & $\begin{array}{l}\text { Patients with } \\
\text { Teflon granuloma }\end{array}$ \\
\hline Cho et al. [21] & 376 & $4(1.1 \%)$ \\
Premsagar et al. [22] & 155 & $2(1.3 \%)^{\mathrm{a}}$ \\
Kureshi and Wilkins [23] & 331 & $7(2.1 \%)$ \\
Chen et al. [24] & 89 & $5(5.6 \%)^{\mathrm{a}}$ \\
Matsushima et al. [25] & 82 & $6(7.3 \%)^{\mathrm{a}}$ \\
Amador and Pollock [4] & 186 & $7(3.7 \%)$ \\
Capelle et al. (2010, & 200 & $3(1.5 \%)^{\mathrm{a}}$ \\
this study) & \multicolumn{2}{l}{} \\
a These studies provided histopathological examination of the Teflon \\
granuloma
\end{tabular}

is growing over time. In single instances, large lesions developed after a delay of several years [33-35].

Chen et al. observed that blood supply to the Teflon granuloma emanated from the tentorium or dura. They concluded that the inflammatory giant cell reaction is induced only when the Teflon felt contacts the tentorium or dura [24]. Matsushima and colleagues, however, thought that the fibrotic reaction is triggered by a distinct adhesion of the Teflon to the trigeminal nerve [25]. Premsagar on the other hand postulated Teflon-induced foreign body reaction to occur in particular when it is in contact with the brainstem [22]. The use of any material to fix the Teflon felt should be discussed as another factor for granuloma formation. However, only the series of Cho et al. could be identified in which histoacryl was used [21]. It remains speculative if fibrin glue may be an additional factor for granuloma formation since it occurred in only three of our 200 patients.

All of the hypotheses, however, suffer from the fact that the causes thought to trigger the development of the chronic inflammation, i.e., contact to the brainstem, to the nerve or to the tentorium or dura are common in MVD of the trigeminal nerve, in general, and they neglect that the majority of patients will not develop granuloma. While bacterial infection has been thought to play a role in a Teflon granuloma in a patient who underwent an endonasal approach for a skull base tumor, there is no clue that this might be relevant in granuloma after MVD [36].

According to our findings (in particular the presence of hemosiderin-loaden macrophages), we suggest that the trigger of the chronic inflammation is small bleeding into the Teflon felt at surgery. Along with the migration of immunocompetent cells into the foreign material, the second step is a foreign body reaction, resulting in the third phase, which implicates a chronic granulomatous inflammation with calcification and tumor growth.

We suggest that repeat posterior fossa exploration might be offered to patients with recurrent trigeminal neuralgia, especially when Teflon granuloma is suspected. One might question why we decided to use again Teflon for interposition between vessel and nerve after removal of the Teflon granuloma. We thought this might be justified after complete removal of the mass and the adhesions, thus bringing the inflammatory process to a halt. With regard to the course of the patients after the second approach, thus far, this algorithm appears to be justified.

Little is known about the outcome after reoperation for trigeminal neuralgia due to Teflon granuloma. Chen et al. [24] described a "cure" in their patients; however, no follow-up times were provided. Some authors recommend ablative procedures to treat recurrent trigeminal neuralgia; however, again no specific outcome for patients with Teflon granuloma is available. Finally, partial sensory rhizotomy has been recommended and performed in some instances [4]. While this procedure might improve or abort paroxysms of trigeminal neuralgia, new or increased facial numbness will invariably develop, and also anesthesia dolorosa might subsequently affect severely the patient's quality of life. We think that given the results which can be achieved by removal of the Teflon granuloma and repeatMVD, this Faustian bargain can be largely avoided, nowadays.

\section{Conclusion}

Teflon granuloma is a rare cause for recurrent facial pain or facial numbness after MVD for trigeminal neuralgia. Early diagnosis of Teflon granuloma is possible by imaging studies. A feasible treatment option is surgical re-exploration and nerve preserving removal of the tefloma.

Conflict of interest There is no conflict of interest of any author.

\section{References}

1. Diener HC, Gendolla A, Katsarava Z (2008) Diagnosis and treatment of head and facial pain. Internist (Berl) 49:1343-1348

2. Gronseth G, Cruccu G, Alksne J, Argoff C, Brainin M, Burchiel K, Nurmikko T, Zakrzewska JM (2008) Practice parameter: the diagnostic evaluation and treatment of trigeminal neuralgia. Neurology 71:1183-1190

3. De Castro AR, de Siqueira SR, Perissinotti DM, de Siqueira JT (2008) Psychological evaluation and cope with trigeminal neuralgia and temporomandibular disorder. Arq Neuropsiquiatr 66:716-719 
4. Amador N, Pollock BE (2008) Repeat posterior fossa exploration for patients with persistent or recurrent idiopathic trigeminal neuralgia. J Neurosurg 108:916-920

5. Barker FG 2nd, Jannetta PJ, Bissonette DJ, Larkins MV, Jho HD (1996) The long-term outcome of microvascular decompression for trigeminal neuralgia. N Engl J Med 334:1077-1083

6. Miller JP, Magill ST, Acar F, Burchiel KJ (2009) Predictors of long-term success after microvascular decompression for trigeminal neuralgia. J Neurosurg 110:617-618

7. Tatli M, Satici O, Kanpolat Y, Sindou M (2008) Various surgical modalities for trigeminal neuralgia: literature study of respective long-term outcomes. Acta Neurochir 150:243-255

8. Zakrzewska JM, Thomas DG (1993) Patient's assessment of outcome after three surgical procedures for the management of trigeminal neuralgia. Acta Neurochir 122:225-230

9. Sheehan J, Pan HC, Stroila M, Steiner L (2005) Gamma knife surgery for trigeminal neuralgia: outcomes and prognostic factors. J Neurosurg 102:434-441

10. Régis J, Metellus P, Hayashi M, Roussel P, Donnet A, Bille-Turc F (2005) Prospective controlled trial of gamma knife surgery for essential trigeminal neuralgia. J Neurosurg 104:913-924

11. Pollock BE, Phuong LK, Gorman DA, Foote RL, Stafford SL (2002) Stereotactic radiosurgery for idiopathic trigeminal neuralgia. J Neurosurg 97:347-353

12. Massager N, Lorenzoni J, Devriendt D, Desmedt F, Brotchi J, Levivier M (2004) Gamma knife surgery for idiopathic trigeminal neuralgia performed using a far-anterior cisternal target and a high dose of radiation. J Neurosurg 100:597-605

13. Jannetta PJ (1967) Arterial compression of the trigeminal nerve at the pons in patients with trigeminal neuralgia. J Neurosurg 107:216-219

14. Jannetta PJ, Tew JM Jr (1979) Treatment of trigeminal neuralgia. Neurosurgery 4:93-94

15. Jannetta PJ (1980) Neurovascular compression in cranial nerve and systemic disease. Ann Surg 192:518-525

16. Jannetta PJ, Robbins LJ (1980) Trigeminal neuropathy-new observations. Neurosurgery 7:347-351

17. Lovely TJ, Jannetta PJ (1997) Microvascular decompression for trigeminal neuralgia. Surgical technique and long-term results. Neurosurg Clin N Am 8:11-29

18. Fujimaki T, Sasaki T, Kirino T (1998) Microvascular decompression. J Neurosurg 88:617-618

19. Jannetta PJ, McLaughlin MR, Casey KF (2005) Technique of microvascular decompression. Technical note. Neurosurg Focus 18:E5

20. Sindou M, Leston J, Decullier E, Chapuis F (2007) Microvascular decompression for primary trigeminal neuralgia: long-term effectiveness and prognostic factors in a series of 362 consecutive patients with clear-cut neurovascular conflicts who underwent pure decompression. J Neurosurg 107:1144-1153

21. Cho DY, Chang CG, Wang YC, Wang FH, Shen CC, Yang DY (1994) Repeat operations in failed microvascular decompression for trigeminal neuralgia. Neurosurgery 35:665-670
22. Premsagar IC, Moss T, Coakham HB (1997) Teflon-induced granuloma following treatment of trigeminal neuralgia by microvascular decompression. Report of two cases. J Neurosurg 87:454-457

23. Kureshi SA, Wilkins RH (1998) Posterior fossa reexploration for persistent or recurrent trigeminal neuralgia or hemifacial spasm: surgical findings and therapeutic implications. Neurosurgery 43:1111-1117

24. Chen J, Lee S, Lui T, Yeh Y, Chen T, Tzaan W (2000) Teflon granuloma after microvascular decompression for trigeminal neuralgia. Surg Neurol 53:281-287

25. Matsushima T, Yamaguchi T, Inoue TK, Matsukado K, Fukui M (2000) Recurrent trigeminal neuralgia after microvascular decompression using an interposing technique. Teflon felt adhesion and the sling retraction technique. Acta Neurochir 142:557561

26. Ashkan K, Marsh H (2004) Microvascular decompression for trigeminal neuralgia in the elderly: a review of the safety and efficacy. Neurosurgery 55:840-850

27. Sekula RF, Marchan EM, Fletcher LH, Casey KF, Jannetta PJ (2008) Microvascular decompression for trigeminal neuralgia in elderly patients. J Neurosurg 108:689-691

28. Chuong R, Piper MA, Boland TJ (1993) Recurrent giant cell reaction to residual Proplast in the temporomandibular joint. Oral Surg Oral Med Oral Pathol 76:16-19

29. Szapiro J Jr, Sindou M, Szapiro J (1985) Prognostic factors in microvascular decompression for trigeminal neuralgia. Neurosurgery 17:920-929

30. Lypka M, Yamashita DD (2007) Exuberant foreign body giant cell reaction to a teflon/proplast temporomandibular joint implant: report of a case. J Oral Maxillofac Surg 65:1680-1684

31. Udeshi M, Bangash H, Gagliardi J (2006) Foreign body giant cell reaction to polytetrafluoroethylene used as interposition material in scaphoid-trapezium arthroplasty. Australas Radiol 50:233-236

32. Tate JR, Belafsky PC, Vandewalker K (2007) Teflon granuloma. Ear Nose Throat J 86:134-136

33. Megerian CA, Busaba NY, McKenna MJ, Ojemann RG (1995) Teflon granuloma presenting as an enlarging, gadolinium enhancing, posterior fossa mass with progressive hearing loss following microvascular decompression. Am J Otol 16:783-786

34. Smucker P, Bonnin JM, Pritz MB (2007) Teflon granuloma with midbrain cysts after microvascular decompression of the trigeminal nerve. Acta Neurochir 149:537-539

35. Toth G, Rubeiz H, Macdonald RL (2007) Polytetrafluoroethylene-induced granuloma and brainstem cyst after microvascular decompression for trigeminal neuralgia: case report. Neurosurgery 61:875-877

36. Soose RJ, Snyderman CH, Kassam AB (2007) Teflon granuloma of the skull base: a complication of endonasal brain surgery. Skull Base 17:247-252 